\title{
1. Introduction to A Modern Guide to Sports Economics
}

Ruud H. Koning and Stefan Kesenne*

Sports economics is now a well-established specialization in economics, with great interest from both academics and practitioners. This book presents modern research in sports economics, and is visible proof of that interest and relevance. The field has dedicated journals such as the Journal of Sports Economics and the International Journal of Sport Finance. Other journals have devoted special issues to sports economics; see for example the Scottish Journal of Political Economy (2015), the Journal of Economic Psychology (2019, volume 75B) and De Economist (2021, issue 1). Sport is considered to be an ideal testing ground for economic hypotheses (the objective of the participant is usually easily established - winning, and feedback from actions is rapid), and it is also interesting and important in its own right. Fan demand, as measured by time spent watching sports in a stadium or on television, is enormous. Understanding the production process underlying a sports contest is an important part of sport consumption. Fans derive utility from discussing the quality of the teams, recent transfers, refereeing errors, individual performance, competitiveness of the contest, etc. with each other. Different aspects of these items are discussed in this book.

The first main chapter, by Fort, elaborates on the development of (European) sports economics. He examines this from an American perspective, but he also looks at the future and stresses the relevance of sports analytics and media policy. The next five chapters relate to competitive balance and attendance. Reade takes a long-term perspective when he analyses attendance patterns at professional football matches in England and Wales from 1888 onwards. Attendance is persistent, which provides support for the hypothesis that fan loyalty is an important determinant. Two chapters by Andreff and Scelles focus on outcome uncertainty fluctuation and match demand. In the first they propose measuring competitive intensity as opposed to competitive balance. In their second chapter they discuss the impact of competitive intensity on fan demand. These two chapters focus on professional football. Kesenne presents an overview of important 
issues regarding competitive balance in any team sports league. Causes and instruments to change competitive balance are discussed. Nalbantis and Pawlowski take a very detailed look at attendance. They moderate the relation between outcome uncertainty and attendance by pricing category and seating quality at football matches. Demand for expensive tickets is primarily driven by fans preferring the ex ante favorite to win, while fans buying inexpensive tickets seem to prefer a home win. Finally, Paul follows up on the importance of sports analytics as identified by Fort. He shows that new shot attempt metrics developed in the National Hockey League have significant positive effects on attendance.

Traditionally, professional sports matches are consumed by attending the match in a stadium. However, during the last 30 years a new channel has emerged. Matches are broadcast live on television. Buraimo, Forrest, McHale and Tena examine determinants of the size of television audiences for English Premier League matches. They show that, for example, championship significance is shown to be an important determinant of viewership. Does traditional gate attendance decrease because of live television broadcasting? This is the topic of the chapter by Buraimo, Owen, and Simmons. They find negative effects of live broadcasting of midweek Champions League and Premier League televised games on attendances at concurrent matches. These two chapters relate to the importance of media policy in sports as also identified by Fort.

The potential economic impact of the organization of sport events is an important topic in the sport economics literature. Three chapters focus on this topic. First, Baade, Baumann and Matheson argue that the 2014 men's football World Cup finals in Brazil increased foreign tourism by roughly 1 million, exceeding expectations. However, the 2016 Summer Olympics in the same country increased tourism by less than 100 thousand tourists, clearly indicating that the economic impact is event-specific. Tourist inflow and hotel occupancy for the 2015 women's World Cup finals in Canada is examined by Stephenson, who finds that visitors to this event displaced other tourists. Pérez assesses another potential impact of events: club teams are obliged to release players when they are invited to play for their national team. What is the effect of the Africa Cup of Nations on competitive balance in European soccer leagues? He documents a differential impact on different leagues.

Professional sport is consumed by watching athletes or teams compete, but recreational sport is produced by participation of the recreational athletes. Frick compares age-performance profiles of professional and recreational marathon runners. Competitive pressures induce elite runners to retire quite early in their career. García and Suárez take a detailed look at different dimensions of sport participation: participation, time, 
frequency and intensity of practice. They relate these dimensions to socioeconomic factors such as education and earnings. Downward, Wicker and Rasciute explore the role of sport as physical activity for health promotion. Interestingly, they take a European rather than a national perspective.

The last six chapters focus on specific issues in sport. First, Sloane discusses labor market restrictions in the four major professional leagues in England (football, cricket, rugby league and rugby union). In an open league with promotion and relegation it is difficult for teams to achieve both financial stability and equality of playing performance. Koning and van Steen follow up on recent literature on refereeing in sports. They look at potential dismissal of red cards, and document significant variation in the probability that a red card given by a specific referee is rescinded. Interestingly, introduction of the video assistant referee (VAR) in the Dutch league in the 2018-19 season has not resulted in significantly lower rates of red cards. Is the overall result of a football match determined by 'class' or 'form'? Szymanski and Wilkinson show that in the English Premier League it is better to have more valuable players than to bank on a continued run of good results. Team dynamics is the topic of the chapter by Humphreys and Yang. Is it possible to shirk in a team when there are repeated games? In a detailed empirical study based on American football they find support for a theoretical model. Does the time between two matches between the same teams matter? Krumer uses a powerful identification strategy to answer this question, using explicit randomization based on a competition schedule. An underdog team that has done well in the first match is more likely to do well in the second match if it follows sooner rather than later. The final chapter, by Goller, Knaus, Lechner and Okasa, again relates to the sports analytics revolution. They develop a machine learning model (building on an Ordered Forest estimator) to estimate probabilities of a home win, draw and away win. The method requires a large data set; but then, big data is an important development, not least in sports!

Sports economics started as an academic field of interest in the United States in the mid-1950s. Until the turn of the century, the center was the United States, even though European academics have contributed to the development. Since then, development in sports economics in Europe has taken off, with a very important role for the series of international sports economics conferences in Gijón, Spain, which brought American and European academics together. It all started with a conference in April 2006, with the participation of famous sports economists such as Roger Noll, Rodney Fort, Robert Baade, Peter Sloane, Stefan Szymanski, Bernd Frick and Bill Gerard. After only a few years, the Gijón conferences ranked among the best and most well-known sports economics conferences in Europe. Furthermore, after each conference all papers were collected and 
published in beautifully edited books. These conferences were organized by Plácido Rodríguez, to whom the sports economics community is greatly indebted. To show the appreciation of all contributors to this volume, this volume is dedicated to Plácido.

Most of the work on this volume was compiled before the COVID-19 pandemic hit the world in 2020. Even though the lockdowns and suspension of sports leagues gave rise to many new questions, these are not taken into account in this book explicitly. However, current developments do touch on the relevance of the chapters relating to television demand.

\section{NOTE}

* Stefan Kesenne passed away unexpectedly on 21 June 2021, while this book was in production. We will miss a good friend, and a great scholar. RHK. 